\title{
Distribuição dos Casos de Leishmaniose Visceral Humana (calazar) em Pernambuco no Ano 2002.
}

\author{
Valdenilson Aguiar ${ }^{1}$, Glaciene Mary da S.Goncalves ${ }^{2}$, Francisco Duarte Farias ${ }^{1}$.
}

\section{INTRODUÇÃO}

A Leishmaniose Visceral Americana ou Calazar é uma doença crônica generalizada, causada por protozoários intracelulares do gênero leishmania. Caracteriza-se por febre, emagrecimento, debilidade progressiva, hepatoesplenomegalia, linfoadenopatia, anemia, leucopenia, podendo evoluir para óbito caso não seja corretamente tratado(OPAS,1997).

É uma endemia que apresenta ampla distribuição, tanto no velho mundo como nas Américas(MS,1996). Inicialmente sua ocorrência era predominantemente rural(OPAS,1997), atualmente a doença é registrada em centros urbanos de médio e grande porte, em área domiciliar ou peridomiciliar(MS,2002).

A sua ocorrência está relacionada a existência de múltiplos fatores: agente etiológico, vetor, reservatório, homem susceptível e fatores ambientais(MS,2002). Se constitui um crescente problema de saúde publica no país e em outras regiões do continente americano(MS,2002).

Casos humanos são registrados desde o México até a Argentina, no Brasil a doença se distribui em 19 estados da federação. A região Nordeste se destaca com o maior número de casos confirmados da doença, $92 \%$ do total de casos registrados no país, seguido pelo Sudeste com 4\%, região Norte 3\% e Centro-Oeste com 1\%(MS,2002).

0 presente estudo, objetiva identificar a atual distribuição dos casos confirmados da doença no estado de Pernambuco, no ano 2002.

\section{OBJETIVOS}

\section{Geral}

Conhecer a distribuição dos casos confirmados de Calazar humano nas mesorregiões geográficas e municípios Pernambucanos no ano 2002.

\section{Específicos}

Identificar o número de casos confirmados de Calazar humano por municípios de Pernambuco.

Identificar o número de casos confirmados de Calazar humano no Estado de Pernambuco, segundo mesorregiões geográficas.

Identificar o coeficiente de detecção do Calazar humano por municípios de Pernambuco.

\section{METODOLOGIA}

\section{Desenho do Estudo}

0 estudo é do tipo descritivo, de corte transversal, realizado em 53 municípios do estado de Pernambuco no ano 2002.

\section{Caracterização da área do estudo - Estado de Pernambuco}

Localização: porção oriental da região Nordeste do Brasil; Clima: atlântico no leste e Semi-árido no Agreste e Sertão; Vegetação:mangue(litoral), Floresta Tropical(zona da mata),Caatinga (agreste e sertão);

População: 8.161.828 habitantes;

Número de municípios: 185;

Densidade demográfica: $80,3 \mathrm{hab} / \mathrm{km}^{2}$;

Área: $98.281 \mathrm{~km}^{2}$ (excluindo a ilha de Ferrando de Noronha);

Mesorregiões do estado de Pernambuco:

\section{Delimitação da àrea de Estudo}

A área de estudo corresponde a 53 municípios no estado de Pernambuco que apresentaram registros de casos confirmados de Calazar humano, segundo relatórios do Sistema Nacional de Informação de Agravos Notificáveis da Secretaria de Saúde do estado.

\section{Variáveis do Estudo}

Município, mesorregião, casos confirmados e coeficiente de detecção.

Procedimentos realizados, processamento e análise dos dados

Definição do município como unidade de análise,sendo considerada a informação mais recente disponibilizado pelo SINANW referente ao ano 2002;

1. Gerência de atenção a doenças de veiculação hídrica e por vetores -Secretaria de Saúde/PE. 2. Divisão de Vigilância Epidemiológica e Ambiental em Saúde FUNASA/PE. 
Elaboração de planilha para coleta dos dados, utilizando o software Excel 97;

Coleta de dados a partir do relatório do SINANW;

Levantamento e aglutinação dos dados de casos confirmados por municípios e mesorregiões geográficas;

Os dados de população utilizados para cálculo do coeficiente de detecção foram do IBGE/2002 e por 100.000 habitantes. Estabelecido faixas de detecção baseados nos resultados encontrados no estado, resultando nos índices: baixo, médio e elevada detecção;

Os dados da divisão geopolítica de Pernambuco utilizados são da FIAM, 1998;

Inserção dos dados em mapas , utilizando o software Corel DRAW 8;

Processamento e análise dos dados através dos softwares Excel 97 e Corel DRAW 8;

Considera-se para este estudo apenas os casos confirmados e classificados por municípios, deixando de ser analisados um total de 07 casos que não foram classificados pelos relatórios do SINANW.

\section{RESULTADOS}

No ano 2002, foram registrados um total de 104 casos confirmados de Leishmaniose Visceral Humana no estado de Pernambuco, distribuídos em 53 municípios(28,7\% do total dos municípios do estado).

Todas as mesorregiões Pernambucanas apresentaram casos confirmados da doença ano 2002, o Agreste destacouse com um quantitativo de 44 casos ou seja, $42,3 \%$ do total registrado no estado.

Com referência as taxas de detecção por municípios Pernambucanos, os resultados variam de 0,1 caso por 100.000 habitantes, como o registrado no município de Recife, até taxas de 53 casos, observado em Betânia, município localizado na mesorregião do Sertão Pernambucano.

0 coeficiente de detecção da doença no estado no ano de 2002, foi de 1,3 casos por 100.000 habitantes.

\section{CONCLUSÃO}

Após a análise dos dados e avaliação dos resultados, concluímos o seguinte:

No que se refere á distribuição dos casos confirmados de Calazar humano por municípios no ano 2002 em Pernambuco, observado uma redução de $40 \%$ no número de municípios com registro da doença e de $69 \%$ do total de casos confirmados no ano 2001 que foi de 336 casos. 0 resultado sugere que não ocorreu expansão da doença no estado no período 2001 a 2002. É importante ressaltar, a necessidade do fato ser melhor avaliado, visando identificar prováveis fatores que corroboraram para a redução do número de casos da doença no estado no ano 2002,como por exemplo: sub-notificação, sazonalidade, dificuldades operacionais do SINANW, entre outros fatores.

Quanto ao número de casos confirmados por mesorregiões, os resultados encontrados foram os esperados, tendo em vista ser a mesorregião do Agreste Pernambucano a que vem apresentando nos últimos 05 anos o maior registro de casos humanos da doença no estado de Pernambuco.

Diante dos resultados encontrados no presente estudo, recomendamos para o estado de Pernambuco a implementação das ações referentes ao conhecimento da distribuição vetorial, das ações de epidemiologia, informação, educação, comunicação e controle de reservatórios e vetores. As referidas ações, devem ser priorizadas na mesorregião do Agreste Pernambucano.

\section{REFERÊNCIAS BIBLIOGRÁFICAS}

Brasil. Controle, Diagnóstico e Tratamento da Leishmaniose Visceral(Calazar) Normas Técnicas. Brasília: Funasa, 1996. 2 ed. 85 p.

.Guia de Vigilância Epidemiológica. Brasília: Funasa, 2002. 5 ed. 842 p.

Fundação de apoio intermunicipal do interior de pernambuco. fiammeso.TXT. Caracterização do espaço geográfico do estado de Pernambuco. Recife 01 jan. 1998.03 disquetes, 31/2pol. Word for Windows 7. 0.

Organizacion Panamericana de la Salud. Manual para el Control da las enfermidades transmisibles . (Washington):OPS, 1997. 541 p (informe oficial de la Asociacón Estadunidense de Salud Pública, n.564). 